\title{
ROTAÇÃO POR ESTAÇÕES COM GAMIFICAÇÃO: IMPACTO NA APRENDIZAGEM DE UM COMPONENTE CURRICULAR HÍBRIDO.
}

JOAÇABA/SC MAIO/2018

\author{
Luciano Fernandes - Unoesc- luciano.fernandes@unoesc.edu.br \\ Scheila Lockstein - Unoesc - scheila.lockstein@unoesc.edu.br \\ Elisabeth Hafner Facin - Unoesc - elisabeth.facin@unoesc.edu.br
}

Tipo: Relato de Experiência Inovadora (EI)

Categoria: Métodos e Tecnologias

Setor Educacional: EDUCAÇÃO SUPERIOR

\begin{abstract}
RESUMO
O objetivo deste estudo é analisar o impacto na aprendizagem dos acadêmicos na estratégia de ensino híbrido denominada rotação por estações. Em uma das estações foi proposto gamificação; utilizando o aplicativo Kahoot. Como a rotação por estações é estruturada de forma que os estudantes passem nas estações em qualquer ordem; a estação da gamificação foi utilizada para verificar o incremento no aprendizado, uma vez que a cada rodada a equipe recebida na estação do game chegava com um incremento de uma rotação. A mensuração dos dados foi realizada pela assertividade das questões e também pela agilidade na resposta. Participaram da atividade 801 alunos, de 8 cursos distintos, divididos em 5 campus da IES. Após análise dos dados foi possível comprovar que quando 0 acadêmico tem contato prévio com o assunto, por meio de leituras elou vídeos, a sua eficiência aumenta, ou seja, a assertividade das questões é maior e o tempo de resposta é menor.
\end{abstract}

Palavras-chave: Ensino Híbrido, Rotação por Estações, Gamificação. 


\section{INTRODUÇÃO}

As mudanças na sociedade contemporânea, oriundas principalmente dos avanços na área das tecnologias digitais de informação e comunicação, têm trazido novas formas de ensinar e aprender. Os nascituros da era digital, envoltos no mundo da tecnologia, demandam do seu mentor/professor, a condução do processo de ensino e aprendizado alinhadas a esta era, com ferramentas e recursos do seu tempo; com o estudante no papel central do processo.

A escola que utiliza métodos tradicionais, que ensina e avalia de forma igual, têm resultados previsíveis, onde o papel do professor está na transmissão de informações, com aulas apenas expositivas, não considera que a sociedade do conhecimento é baseada em competências cognitivas, pessoais e sociais, e que exigem proatividade, colaboração, personalização e visão empreendedora. (MORÁN, 2015).

Com a rápida evolução da internet e a divulgação aberta promovendo o acesso a uma variedade de materiais e informações, é possível aprender em qualquer lugar, a qualquer hora e com o mais variado perfil de pessoas. Neste contexto, para que as instituições se mantenham, identifica-se a necessidade de rever a sua forma de atuação. São fundamentais projetos pedagógicos atualizados, com metodologias atraentes e eficientes, profissionais capacitados, materiais que ultrapassem a barreira da qualidade, que sejam interessantes, elaborados de acordo com o perfil atual, contemplando as competências necessárias aos egressos, e que possuam plataformas adaptativas para ajudar os educandos nas suas necessidades.

Para ajudar a romper essa barreira entre o tradicional e o contemporâneo, Staker e Horn (2012), definem o ensino híbrido como um programa de educação formal que mescla momentos em que o aluno estuda os conteúdos e instruções usando recursos on-line, e outros em que o ensino ocorre em uma sala de aula, podendo interagir com outros alunos e com o professor. As metodologias participativas vem auxiliar nos momentos presenciais de interação entre os pares e com o professor, pois de acordo com Morán (2015), elas são ponto de partida para angariar processos mais avançados de reflexão, de integração cognitiva, de generalização e de reelaboração de novas práticas.

Diante deste desafio e com o intuito de deixar o ambiente escolar mais atraente, por meio das metodologias participativas, propõe-se a discussão do ensino híbrido, utilizando em um primeiro encontro presencial do componente curricular de Ética e Sociedade, o modelo de rotação por estações, incluindo em uma das estações a gamificação, com o objetivo de analisar níveis médios de acertos e a contribuição de 
cada rotação na aprendizagem. A experiência realizada envolveu cinco Campi da Instituição de Ensino Superior (IES) e 801 alunos distribuídos em 8 cursos distintos.

\section{OBJETIVOS}

\section{Objetivo geral}

Analisar o impacto na aprendizagem dos acadêmicos na estratégia de rotação por estações com gamificação em um componente curricular híbrido.

\section{Objetivos específicos}

- Computar os índices de acerto em cada campus e a cada rotação;

- Relacionar os níveis de acerto do campus com as rotações aplicadas;

- Correlacionar o tempo de resposta com assertividade das questões em cada campus por rotação;

- Analisar os níveis de eficiência em cada rotação na estação do game.

\section{REFERENCIAL TEÓRICO}

Segundo Morán (2015), os avanços tecnológicos e as mudanças de perfil dos alunos, levam a necessidade de alteração do modelo disciplinar. O modelo adotado pelas Instituições de ensino superior deve ser mais centrado em aprender ativamente com problemas, criar desafios significativos, jogos, atividades diferenciadas, leituras e projetos combinando tempos individuais e coletivos, exigindo uma mudança de configuração do currículo, da participação dos professores, da organização das atividades didáticas, da organização dos espaços e tempos. (MORÁN, 2015).

Um modelo já utilizado em inúmeras instituições brasileiras e principalmente de outros países é o ensino híbrido, que "é um programa de educação formal no qual um aluno aprende, pelo menos em parte, por meio do ensino online, com algum elemento de controle do estudante sobre o tempo, lugar, modo e/ou ritmo do estudo, e pelo menos em parte em uma localidade física supervisionada, fora de sua residência". (CHRISTENSEN; HORN; STAKER, 2015, p.7).

Em conformidade com Morán (2015),com a aplicação deste modelo, algumas dimensões estão sendo evidenciadas: (a) o modelo blended: semipresencial, flexível, sem planejamentos enrijecidos, mesclando física e virtual, individual e em grupos, sempre de acordo com a necessidade; (b) metodologias ativas: práticas, atividades, 
jogos, projetos expressivos, para que o aprendizado aconteça em conjunto e individuais para que se tenha personalização; (c) modelo on-line com uma mistura de colaboração e personalização. Cada aluno desenvolve um percurso mais individual e participa em determinados momentos de atividades de grupo. Uma parte da orientação será via sistema (plataformas adaptativas com roteiros semiestruturados, que respondem as questões mais previsíveis) e a principal será feita por professores e tutores especialistas, que orientarão os estudantes nas questões mais difíceis e profundas.

Apropriando-se de todas estas inovações na arte de ensinar e aprender a aprender; no Brasil, mesmo nos cursos ofertados na modalidade presencial, há uma flexibilidade por parte do Ministério da Educação em permitir a oferta de disciplinas na modalidade integral ou parcialmente a distância; desde que não ultrapasse $20 \%$ (vinte por cento) da carga horária total do curso determinado na Portaria nำ1.134 (BRASIL, 2016).

Desta forma, utilizando a metodologia da sala de aula invertida, o discente se apropria do tempo de auto-estudo para fazer a parte dos estudos individuais (pré-aula) e os momentos presenciais para as discussões com colegas, professor e aprofundamentos.

De acordo com Christensen, Horn e Staker (2015), dentre os principais modelos adotados no ensino híbrido, apresenta-se quatro categorias: modelo de rotação; modelo flex; modelo A La Carte; modelo Virtual enriquecido. No modelo de Rotação por estações os estudantes são organizados em grupos, e cada um desses grupos realiza uma tarefa de acordo com os objetivos do professor para a aula. Um dos grupos estará envolvido com propostas on-line que, de certa forma, independem do acompanhamento direto do professor. É importante notar a valorização de momentos em que os alunos possam trabalhar colaborativamente e momentos em que trabalhem individualmente. Após determinado tempo, previamente combinado com os estudantes, eles trocam de grupo, e esse revezamento continua até que todos tenham passado por todos os grupos (BACICH; MORAN, 2015).

As atividades planejadas não seguem uma ordem de realização, sendo de certo modo independentes, embora funcionem de maneira integrada para que, ao final da aula, todos tenham tido a oportunidade de ter acesso aos mesmos conteúdos $(\mathrm{BACICH}$; MORAN, 2015).

O uso de diferentes recursos pedagógicos e de novas estratégias de ensino são fatores fundamentais para o sucesso na aprendizagem. Tem o papel de reduzir cada vez mais o distanciamento entre discente e docente. A transformação se faz favorável quanto ao uso de uma metodologia ativa e novas práticas pedagógicas. A gamificação, pode ser 
uma alternativa.

Os jogos costumam instigar o interesse do jogador por apresentar alguns desafios, obstáculos e limites, assim como, também, a possibilidade de superá-los. Os games foram criados inicialmente com a função de entretenimento e se tornaram bastante popular no Brasil, os quais a maioria dos jovens se identificam. Eles têm grande capacidade de atrair e reter a atenção dos alunos estuda-se as várias possibilidades dos games serem usados como ferramentas para potencializar o processo de ensino e de aprendizagem nas escolas (SALES, 2017).

\section{PROCEDIMENTOS METODOLÓGICOS}

O componente curricular de Ética e Sociedade é classificado internamente na IES como um componente institucional. Desta forma todos os cursos trabalham com a mesma ementa, carga horária e modalidade. No primeiro semestre de 2018 ele foi oferecido nos cinco (5) campi da instituição, envolveu 8 cursos: Design, Direito, Educação Física, Enfermagem, Engenharia Civil, Fisioterapia, Nutrição e Zootecnia.

Diante deste cenário e consoante aos projetos políticos pedagógicos dos cursos, ele foi oferecido de forma híbrida - $60 \%$ a distância e $40 \%$ presencial e a estratégia utilizada foi a da Sala de Aula Invertida também denominada de Flipped Classroom. Para o planejamento do primeiro encontro presencial, foco deste estudo, estiveram envolvidos 0 professor, o coordenador da EaD e o Núcleo de Apoio Pedagógico da IES. Para a execução da atividade, somou-se ao grupo de desenvolvimento a equipe de tutores da instituição.

Dentro da metodologia escolhida, a estratégia para o primeiro encontro foi a rotação por estações. Ela foi estruturada em cinco etapas: vídeo; texto 1; desafio; texto 2 e game. As equipes foram organizadas de forma aleatória, assim uma mesma equipe foi composta por estudantes de diversos cursos. As temáticas das estações eram todas afetas aos conceitos de ética e moral e cada grupo de estudantes avançou nas estações em uma sequência própria conforme a Quadro 1.

Quadro 1 - Fluxo das rotações e atividades em cada estação por equipes 


\begin{tabular}{|l|c|c|c|c|c|}
\hline Estação / Equipe & $\mathbf{1}$ & $\mathbf{2}$ & $\mathbf{3}$ & $\mathbf{4}$ & $\mathbf{5}$ \\
\hline Estação 1 & Vídeo & Texto I & Desafio & Texto ॥ & Kahoot \\
\hline Estação 2 & Texto I & Desafio & Texto ॥ & Kahoot & Vídeo \\
\hline Estação 3 & Desafio & Texto II & Kahoot & Vídeo & Texto I \\
\hline Estação 4 & Texto ॥ & Kahoot & Vídeo & Texto I & Desafio \\
\hline Estação 5 & Kahoot & Vídeo & Texto I & Desafio & Texto ॥ \\
\hline
\end{tabular}

Fonte: os autores.

Os dados para este estudo foram angariados na estação do game. Estrategicamente utilizou-se para esta etapa o aplicativo on-line denominado Kahoot, que mensura além dos acertos, o tempo que cada acadêmico leva para responder cada questão. Desta forma, tem-se um parâmetro de eficiência no acerto das questões, ou seja, quanto mais rápido acertar a questão, maior é a eficiência.

A fim de garantir que todos os estudantes entendessem a forma de trabalhar com o Kahoot, a equipe preparou uma questão para ensaio; minimizando com isto os erros por falta de conhecimento no funcionamento do aplicativo. Desta forma, foram criadas ao todo 8 questões, mas validadas para este estudo apenas 7 (da segunda a oitava questão). A presencialidade dos estudantes no dia da aula foi de $84,2 \%$; representando um total de 801 acadêmicos em 5 campi, conforme representa a Quadro 2.

Quadro 2 - Alunos matriculados/presentes por campus

\begin{tabular}{|l|c|c|c|}
\hline Campus & Matrículas & Presentes & $\begin{array}{c}\% \\
\text { Presença }\end{array}$ \\
\hline Campus A & 171 & 121 & $70,8 \%$ \\
\hline Campus B & 249 & 214 & $85,9 \%$ \\
\hline Campus C & 290 & 263 & $90,7 \%$ \\
\hline Campus D & 120 & 101 & $84,2 \%$ \\
\hline Campus E & 121 & 102 & $84,3 \%$ \\
\hline $\begin{array}{l}\text { Total de } \\
\text { alunos }\end{array}$ & $\mathbf{9 5 1}$ & $\mathbf{8 0 1}$ & $\mathbf{8 4 , 2 \%}$ \\
\hline
\end{tabular}

Fonte: os autores.

\section{APRESENTAÇÃO E DISCUSSÃO DOS RESULTADOS}

As análises dos resultados e as discussões embasadas no referencial teórico e nos procedimentos metodológicos apresentados em tópicos anteriores, foram organizados para atender aos objetivos deste estudo. 
O Quadro 3 apresenta os níveis de acerto por campus a cada rotação na estação da gamificação.

Quadro 3 - Níveis de acerto por campus a cada rotação

\begin{tabular}{|l|c|c|c|c|c|c|}
\hline Campus & Rotação 1 & Rotação 2 & Rotação 3 & Rotação 4 & Rotação 5 & Média \\
\hline Campus B & $71,4 \%$ & $87,1 \%$ & $87,8 \%$ & $83,3 \%$ & $86,5 \%$ & $83,2 \%$ \\
\hline Campus E & $78,7 \%$ & $84,0 \%$ & $80,2 \%$ & $65,8 \%$ & $81,9 \%$ & $78,1 \%$ \\
\hline Campus C & $67,7 \%$ & $81,7 \%$ & $78,3 \%$ & $77,3 \%$ & $84,0 \%$ & $77,8 \%$ \\
\hline Campus D & $67,0 \%$ & $72,8 \%$ & $69,9 \%$ & $81,4 \%$ & $81,6 \%$ & $74,5 \%$ \\
\hline Campus A & $74,0 \%$ & $66,7 \%$ & $68,6 \%$ & $85,7 \%$ & $71,4 \%$ & $73,3 \%$ \\
\hline Média Rotação & $71,7 \%$ & $78,4 \%$ & $77,0 \%$ & $78,7 \%$ & $81,1 \%$ & $77,4 \%$ \\
\hline
\end{tabular}

Fonte: os autores.

Por meio dele é possível observar que a rotação 1 apresentou o menor índice de acerto $(71,7 \%)$ enquanto que a melhor média pode ser verificada na rotação 5 ( $81,1 \%)$. Isto comprova a eficiência da atividade, em termos de aprendizado; ou seja, a medida que os estudantes vão avançando nas estações o índice de acerto também tende a aumentar e como na última rotação os acadêmicos já haviam passado por todas as estações de estudo e aprofundamento (vídeo, texto I, desafio e texto II), isto reforça a importância do estudo prévio.

Observando o desempenho dos índices de acerto por campus, verifica-se que os campi $\mathrm{B}, \mathrm{E}$ e C apresentaram média superior à geral. Os campi D e A tiveram desempenho médio satisfatório acima de $70 \%$ indicando que a aprendizagem foi significativa. Assim, a ferramenta de gamificação permitiu além de identificar os níveis de acerto, o tempo médio de resposta; conforme demonstra o Quadro 4.

Quadro 4 - Tempo médio de resposta por campus e rotação

\begin{tabular}{|l|c|r|r|r|r|r|}
\hline Descrição & Rotação 1 & Rotação 2 & Rotação 3 & Rotação 4 & Rotação 5 & Média \\
\hline Campus B & 12,4 & 7,5 & 6,0 & 4,9 & 5,7 & 7,3 \\
\hline Campus A & 11,4 & 11,1 & 15,7 & 7,9 & 5,6 & 10,3 \\
\hline Campus D & 15,5 & 10,7 & 10,6 & 12,9 & 9,9 & 11,9 \\
\hline Campus C & 13,2 & 12,6 & 11,9 & 12,6 & 11,0 & 12,3 \\
\hline Campus E & 19,0 & 21,4 & 14,0 & 15,7 & 15,3 & 17,1 \\
\hline Tempo médio & $\mathbf{1 4 , 3}$ & $\mathbf{1 2 , 6}$ & $\mathbf{1 1 , 6}$ & $\mathbf{1 0 , 8}$ & $\mathbf{9 , 5}$ & $\mathbf{1 1 , 8}$ \\
\hline
\end{tabular}

Fonte: os autores. 
Percebe-se pelo Quadro 4 que os alunos que passaram inicialmente pela estação gamificada tiveram o maior tempo médio de resposta e a medida em que foram rotacionando em outras estações inicialmente, o tempo médio de respostas diminuiu significativamente.

Avaliando o desempenho por campus, em relação ao tempo médio de resposta, observase que o campus $B$ apresentou excelentes índices, mesmo nas rotações iniciais. $O$ campus $\mathrm{E}$ apresentou índices insatisfatórios em relação à média dos demais campi com índices dispersivos na média, em todas as questões.

Conforme os dados dos Quadros 3 e 4, percebe-se um aumento médio nos índices de acerto acompanhado de uma redução do tempo médio de resposta dessas questões. Quanto maior o número de estações com outras atividades acessadas antecipadamente em relação a estação do game, infere-se uma aprendizagem mais significativa dos alunos participantes daquele grupo.

Como forma de verificar a eficiência nas respostas buscou-se identificar um padrão que indicasse em que níveis a metodologia utilizada, pode contribuir para uma aprendizagem significativa para o aluno. A identificação do padrão de eficiência se deu pela relação entre a porcentagem (\%) do nível de acerto pelo tempo médio de acerto. Por essa relação e partindo da premissa que quanto maior a porcentagem (\%) de acerto e menor o tempo de resposta, maior será o resultado do indicador, apresenta-se o Quadro 5:

Quadro 5 - Padrão de eficiência média por campus e questão

\begin{tabular}{|l|c|c|c|c|c|c|c|c|}
\hline Campus & EQ2 & EQ3 & EQ4 & EQ5 & EQ6 & EQ7 & EQ8 & Média \\
\hline Campus A & $4,0 \%$ & $14,1 \%$ & $17,3 \%$ & $9,3 \%$ & $25,6 \%$ & $25,4 \%$ & $4,2 \%$ & $14,3 \%$ \\
\hline Campus B & $4,0 \%$ & $14,1 \%$ & $14,7 \%$ & $8,9 \%$ & $21,5 \%$ & $21,7 \%$ & $5,1 \%$ & $12,9 \%$ \\
\hline Campus E & $3,4 \%$ & $12,8 \%$ & $12,8 \%$ & $7,0 \%$ & $20,7 \%$ & $20,0 \%$ & $4,7 \%$ & $11,6 \%$ \\
\hline Campus D & $3,6 \%$ & $12,4 \%$ & $12,5 \%$ & $6,6 \%$ & $21,0 \%$ & $19,4 \%$ & $4,9 \%$ & $11,5 \%$ \\
\hline Campus C & $3,7 \%$ & $12,5 \%$ & $12,0 \%$ & $6,3 \%$ & $20,1 \%$ & $18,6 \%$ & $5,0 \%$ & $11,2 \%$ \\
\hline Média/Campus & $3,7 \%$ & $9,7 \%$ & $11,1 \%$ & $6,3 \%$ & $23,0 \%$ & $20,9 \%$ & $5,5 \%$ & $11,5 \%$ \\
\hline
\end{tabular}

Fonte: os autores.

$\mathrm{Na}$ análise do Quadro 5 por campus e questão aplicada, observa-se que o padrão de eficiência foi melhor aplicado nas questões EQ6 e EQ7, respectivamente. O menor índice de eficiência foi detectado na $E Q 2$, o que era previsto, pois a questão $E Q 1$ foi descartada para fins de reconhecimento e aplicação do uso da ferramenta de gamificação antes de aplicar os testes efetivamente e a questão EQ2 trás indícios que alguns alunos ainda não tinham dominado a ferramenta até aquele momento. As 
questões EQ5 e EQ8 apresentaram baixo padrão de eficiência, contudo, não foi objeto de estudo analisar as causas em nível de questão aplicada. Conforme pode ser observado no quadro 5 e considerando o desempenho do campus, observa-se que 0 campus A apresentou melhor resposta em relação ao padrão de eficiência com um índice de $14,3 \%$, seguido do campus B com 12,9\% de padrão de eficiência. Os demais campus apresentaram uma média similar.

O Gráfico 1, apresenta o crescimento no padrão de eficiência média por rotação. Com base neste gráfico e com o padrão de eficiência calculado por rotação, é possível identificar o índice em cada rotação na estação gamificada. A rotação 1 apresenta inicialmente um índice de 8,6 e enquanto avança às rotações seguintes, o padrão de eficiência segue uma linha crescente até a estação 5 que traz um índice de 14,3\%, ou seja, um crescimento de $66 \%$ em relação a primeira rotação.

Gráfico 1 - Crescimento no padrão de eficiência média por rotação

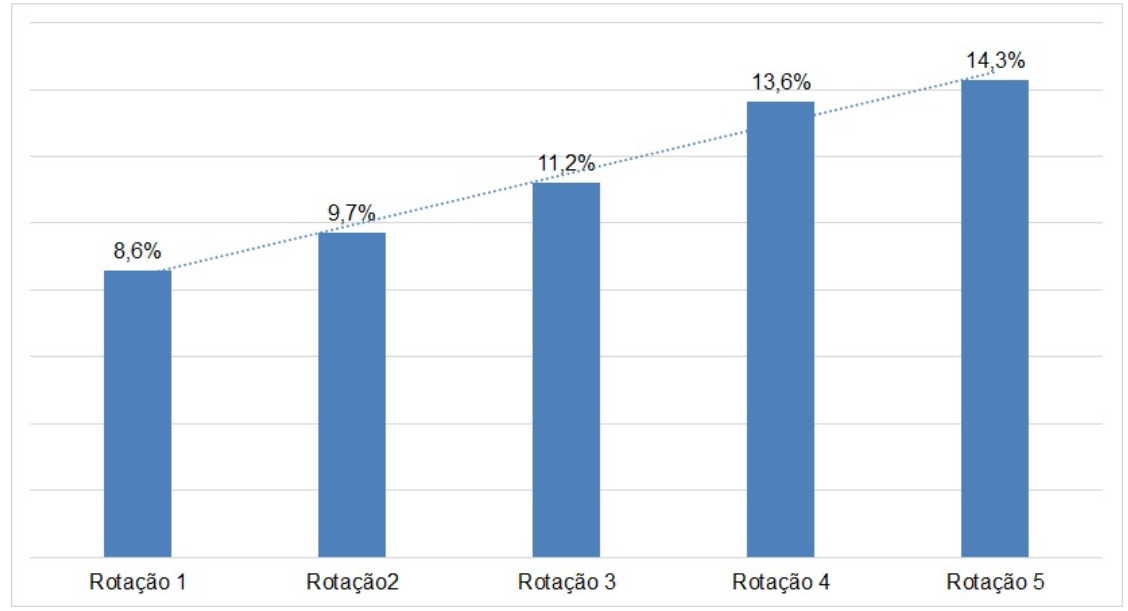

Fonte: os autores.

Infere-se que a medida em que o aluno avança nas estações de trabalho realizando as atividades previstas para cada uma, seu desempenho na estação do game, cresce nessa mesma proporção. Dessa forma, pressupõe-se que a utilização da metodologia ativa de sala de aula invertida com rotação por estações, e o engajamento nas ferramentas de gamificação, tornam o processo ensino e aprendizagem mais dinâmico, interessante para 0 estudante e principalmente, proporcionam uma aprendizagem significativa.

\section{CONSIDERAÇÕES FINAIS}

Entende-se que o objetivo geral foi atendido, pois os dados da gamificação comprovam 
que a medida que os acadêmicos avançam nas estações, seu aprendizado vai se tornando mais efetivo. Existem algumas divergências entre os diversos campus da IES, que precisam ser analisados com mais cautela, entretanto é possível estar relacionado com uma falta de conhecimento prévio ou engajamento da turma na atividade.

Os resultados deste estudo ajudam a comprovar, além dos objetivos propostos, que se a metodologia ativa/participativa de sala de aula invertida for aplicada e se a realização de atividades prévias acontecerem efetivamente, o participante terá maior domínio para elucidar de forma eficiente às questões aplicadas na gamificação, uma vez que no modelo proposto o estudante não teve em nenhum momento aula expositiva/dialogada, ele foi apenas norteado pelas estações, e avançou por meio dos seus próprios conhecimentos e das discussões com sua equipe.

\section{REFERÊNCIAS BIBLIOGRÁFICAS}

BORGES, S. d. S.; REIS, H. M.; DURELLI, V. H.; BITTENCOURT, I. I.; JAQUES, P. A.; ISOTANI, S. Gamificação aplicada à educação: um mapeamento sistemático. Simpósio Brasileiro de Informática na Educação-SBIE. 2013. v. 24, n. 1, p. 234.

CHRISTENSEN, C. M., HORN, M. B., STAKER, H. Ensino Híbrido: uma Inovação Disruptiva? Uma introdução à teoria dos híbridos. Clayton Christensen Institute. 2013. Disponível em:

?https://www.pucpr.br/wp-content/uploads/2017/10/ensino-hibrido_uma-inovacaodisruptiva.pdf?Acesso em: 26 abr. 2018.

MORÁN, J. M. Mudando a educação com metodologias ativas. Coleção Mídias Contemporâneas Convergências Midiáticas, Educação e Cidadania: aproximações jovens, $\quad v . \quad 2, \quad 2015.2$ Disponível em: ?http://www2.eca.usp.br/moran/wp-content/uploads/2013/12/mudando_moran.pdf? Acesso em: 24 abr. 2018.

SALES, G. L., CUNHA, J. L. L., GONÇALVES, A. J., SILVA, J. B., SANTOS, R. L. Gamificação e ensinagem híbrida na sala de aula de Física: Metodologias ativas aplicadas aos espaços de aprendizagem e na prática docente. CONEXÃO, Ciência e Tecnologia. Fortaleza, 2017. 